\section{DETAIL IN SURGERY.}

\section{BY T. PRIDGIN TEALE, M.A. OxoN., F.R.C.S. ENG. F.R.S.,}

CONSULTIYG BURGKON TO THE LEEDS GENERAL INFIRMART.

\section{I.-OPERATIONS FOR HAMORRHOIDS.}

Mx life as a surgeon has been long enough to have seen nearly the whole series of methods by which hæmorrhoids have been dealt with-in modern times, at any rate.

In the earlier operations nitric acid was employed and was applied, without anæsthetic, manacles, or Clover's crutch, to hæmorrhoids protruding from the anus as a result of straining over hot water in a night commode. As an improvement in the nitric acid method I was taught by my father to introduce into the rectum one of Weiss's dilators of the female urethra and then after this preliminary step to apply the acid to the diseased portion of the anal canal whilst thus dilated. Two advantages were gained by this modification: firstly, the freedom of the surgeon from dependence upon the goodwill of the bæmorrhoids for their convenient extrusion ; and, secondly and mainly, the thorough dilatation of the sphincter, with its security against subsequent spasmodic contraction apon a mucous membrane which was often both protruding and cauterised. This plan was probably a reaction from an older method of ligature in which the strangled piles had to slough off and which not rarely ended in pyæmia.

My next stage of experience was with Smith's clamp and cautery. To this I held for some years, but the method did not entirely satisfy me, as occasionally there was bleeding into the rectum from the seared stump. About this period my colleague Mr. Walter Brown returned to Leeds as resident surgical officer to the infirmary. He told me of the operation in use at the South London Hospital, where he had recently filled a similar post, in which the hæmorrhoid was transfixed at its base, very firmly tied, and cut away close to the ligature. I thenceforth adopted the plan and made use of it until it was superseded in my practice by what I consider to be the far more satisfactory operation which I have now to describe. To this operation, which I have now used exclusively for the last fourteen yeare, I was led by four main considerations. 1 . The manner in which hæmorrhoids present themselves externally, becoming as accessible as any ordinary growth or tumour on the surface of the body on dilatation of the sphincter, a step I had from a very early time been accustomed to take as a preliminary to all operations on the lower part of the rectum. 2. The method of Coates, which had much impressed me. It consisted in clamping the hremorrhoid, in cutting it off close to the clamp, and, as a final stage, in closing up the raw edges and bleeding surfaces by ligatures with the clamp still in situ instead of arresting the bleeding by cautery. 3. The establishment of a further extension of excision of hremorrhoids by Whitehead of Manchester, who proposed the complete excision of the anal ring of hæmorrhoidal mucous membrane, the bleeding being controlled by ligature and the union of the divided margins being attained by suture. 4. The development of the convenient volsella forceps which I had devised for holding down the os and cervix uteri when dilating and curetting the uterus and which command a complete mastery over the hæmorrhoids during excision. These four considerations chiefly influenced me in deciding to depart from the procedures in vogue at the time.

Let me now give a description of the details of the operation itself : 1. Believing dilatation of the sphincter ani to be, along with tooth-drawing and reduction of dislocation, the kind of proceeding in which chloroform is attended with more than its usual risk I would urge ether empkatically as the anesthetic. 2. The lithotomy position, maintained by manacles and Clover's crutch. 3. Commence, as a matter of course, by dilatation of the sphincter ani, which not only brings the hæmorrhoids into view but is a security against spasmodic disturbance of the wound subsequently to the operation. 4. Grasp the most prominent hæmorrhoid at each extremity by a volsella forceps and hold it securely during the operation. This gives the surgeon perfect command both during excision and whilst completing the operation by suture. 5. Hxcise the hæmorrhoid with curved scissors by marking out and partially dissecting off a shallow flap, firstly, on the mucous membrane side and then on the cutaneous side and then excise the hæmorrhoidal mass. 6. Having tied any obviously pulsating vessels, bring the two sides of the wound together by continuous sutare in the following manner : commencing about $\frac{1}{2}$ in. from one end, let a continuous suture of fine catgut be passed rather deeply so as to bring the whole surface of the wound together and to control any oozing that may be taking place. Terminate this sutare about $\frac{1}{2}$ in. from the other end of the wound but neither tie it nor fix it anywhere. On the contrary, secure it for the time being only by clip forceps, after having drawn it tightly enough to stop all hamorrhage. 7. In like manner deal with a second or even, if necessary, a third bæmorrhoid, taking care to leave about $\frac{1}{2}$ in. of mucous membrane between each wound. 8. Finally, remove the clips from the sutures, which are then cut, leaving about 1 in. protruding at either end. 9. As a rule the sutures disappear and do not need removal. If they do not they can be pulled out without difficulty at the end of a few days, having no fixed point. 10. The after-dressing is practically nil. Some cotton wool is placed between the buttocks to absorb any oozing of blood or serum, but no lint or other dressing is introduced into the anus. This is absolute and de rigueur.

Advantages claimed for this method-Having had many years' experience of nitric acid, of clamp and cautery, and of tying with excision, whilst I have had fifteen years' experience of the method just described, I feel that I may claim for the latter the motto, "Cito, tato et jucunde." Cito, if not in the actual operation, at any rate in rapidity of recovery; tuto, in the absolute security against bæmorrhage and the increased security against septic accidents-not unknown in the old days of ligature-owing to healing by first intention; and jucunde, by reason both of the lessened after-pain and of the greatly reduced tendency to retention of urine, the after-pain being often capable of being reduced to insignificance by very careful soaking of the wound before stitching by a strong carbolic solution $(1$ in 30$)$

I am told that retention of urine is common, indeed, almost expected as a matter of course, where bæmorrhoids have been removed by ligature or by cautery. It is comparatively rare after the operation I have been describing, which has also the advantage over Whitehead's of being tree from the risk of subsequent cicatricial stricture and is at the same time equally applicable to any degree of hæmorrhoids, however extensive.

One may ask how it came about in former days that cautery and ligature were used and not excision. Purely, I believe, from fear of hæmorrhage after operation, for in days when dilatation of the sphincter as a preliminary to removal of bæmorrhoids was practically unknown and efficient volsella forceps for holding the cut surface in view were uninvented the danger was a very real one. An open wound with a bleeding vessel inside a rectum guarded by a contracted sphincter used sometimes in those earlier days to produce a hæmorrhage at once dangerous and concealed. It was to meet this evil that ligature of the whole hæmorrhoid, destruction by nitric acid, and the method of clamp and cautery were invented. But now that we dilate the sphincter, that we have means of holding any amount of hæmorrhoid in view, that we arrest the bleeding of visible vessels by catgut ligature, and can bring the cat surfaces into firm apposition by a suture which either is absorbed or can be pulled away after a few days, the need for these more primitive details seems to have not only lessened but entirely disappeared.

Leeds.

\section{A METHOD OF PROLONGING NITROUS OXIDE ANESTHESIA IN DENTAL} PRACTICE. ${ }^{1}$

BY HARVEY HILLIARD, M.R.C.S. ENG., L.R.C.P. LOND., ASSISTANT ANASTHETIST TO THE DENTAL HOBPITAL OF LONDON.

AN IISTHETISTS are agreed that nitrous oxide would be a perfect anæsthetic for dental procedures but for the brevity, after the removal of the face-piece, of the available anæsthesia produced by its inhalation. Hitherto, therefore, only operations of the shortest duration could be attempted where nitrous oxide has been employed, while in those cases 
requiring an anæesthesia of two to three minutes' duration the nitrous oxide has to be in the vast majority of cases supplemented with the use of ether. Since, however, ether is so liable to be followed by unpleasant after-effects, is so pungent in odour that it clings about the operator's room all day, and since so much preparation of the patient is necessary before the drug can be administered, it is often deemed advisable to perform the operation at the patient's own house in order to minimise these many disadrantages. With nitrous oxide, however, we have practically none of these drawbacks. After-effects, if present, are of such a transient nature that a patient can walk home comfortably within a few minutes of the administration; the gas is without odour and is not unpleasant to inhale; and, moreover, little or no preparation is necessary prior to its inhalation. It is obvious, therefore, that if an anæsthesia of several minutes' duration, after the removal of the face-piece, can be obtained with nitrous oxide, by whatever means, this agent will be used with increasing frequency, and that it will only be supplemented in those cases where an unusually prolonged narcosis is required, as, for instance, in extensive immediate torsions, regulations, and multiple extractions. Up to the present time the means adopted for prolonging the anæsthetic effect of nitrous oxide have been very imperfect, being based for the most part upon the principle of preventing the elimination of the gas, thereby obtaining merely a slightly prolonged anæsthesia; but by preventing this elimination we must prevent or impede respiration also. Such methods, for instance, as pushing backward the lower jaw together with the tongue, thereby closing the orifice of the larynx, or by passing a sponge upon a holder backwards and downwards into the pharynx, produce very marked congestion and cyanosis, with jactitation-in fact, the signs of impending asphyzia. The patient under these circumstances is in a dangerous condition; there is great engorgement of the venous system and right side of the heart, and should there be present any degree of valvular cardiac disease the heart muscle might be unable to cope with the extra strain thrown upon it and the administration might possibly terminate fatally. In almost every reported case of death occurring during the exhibition of nitrous oxide it has resulted from obstructed respiration and consequent asphyzia. We are always very careful, therefore, when administering the gas to patients suffering from valvular disease of the heart not only to ensure perfect freedom of respiration, but also to allow a due admixture of air or oxygen, in order that all jactitation, cyanosis, and cardiac engorgement may be avoided. There is also another grave objection to this mode of prolonging nitrous oxide anæsthesia by preventing elimination, for, as pointed out above, it produces much congestion and cyanosis and this relieves itself locally by increased hamorrhage from the gums and empty tooth-sockets, so that the patient's mouth rapidly fills with blood, whereby the operator is much hampered or even forced to abandon the operation, as there is not sufficient time for systematic sponging. Further, unless the patient's head be kept in such a position that the lower jaw and floor of the mouth form a sort of reservoir for the collection of this blood, it will gravitate backwards and at the first inspiration (which is always of .unusual depth) it will probably be sucked into the air-pas. sages, necessitating immediate tracheotomy to save the patient's life. It should always be our aim, therefore, to maintain the patient's head in the most convenient position for the operator consistent with the safety of the patient, but where the above methods are adopted the operator has to work in an unfarourable position, and thus the ultimate gain in time is practically of no value owing to the increased difficulties of the extractions.

The late Mr. Clover, aware of the advantages of obtaining a prolonged anæsthesia with nitrous oxide in dental surgery, made experiments with a "nose-piece," by means of which he hoped to continue the administration of gas and thus to prolong its anæsthetic action during operations on the mouth after the ordinary face-piece had been removed. To this end, when the patient was fally anæsthetised, he fitted over the nose a small accessory inhaler, to which nitrous oxide was supplied by means of a stopcock and tube communicating with a gasometer. He expected that sufficient gas would be inspired through the nose to maintain an anæsthesia already produced by the ordinary method and thus to enable the surgeon to undertake longer operations upon the jaws than could otherwise have been attempted except under the influence of ether. The results did not prove sufficiently satisfactory and $\mathrm{Mr}$. Clover abandoned the idea. The apparatus was difficult to keep properly adjusted, so much air was breathed through the month that the anæsthesia was uncertain, and finally the gas could not be supplied at sufficient pressure to obviate this evil without being likely to cause damage to the olfactory region, the frontal or even the maxillary sinuses. Having found that prolonged administration of nitrous oxide for ordinary surgical procedures was attended with the best results, I attempted to devise a method whereby this anæsthetic could be employed in extensive operations in dental surgery, and I soon discovered that the only channel for the convenient administration of the gas after the removal of the face-piece was by means of a tube passed along the inferior meatus of the nose. First, a small-sized celluloid female catheter seemed to be the most suitable instrument for this purpose; but this was discarded owing to its rigidity, for a surprisingly large

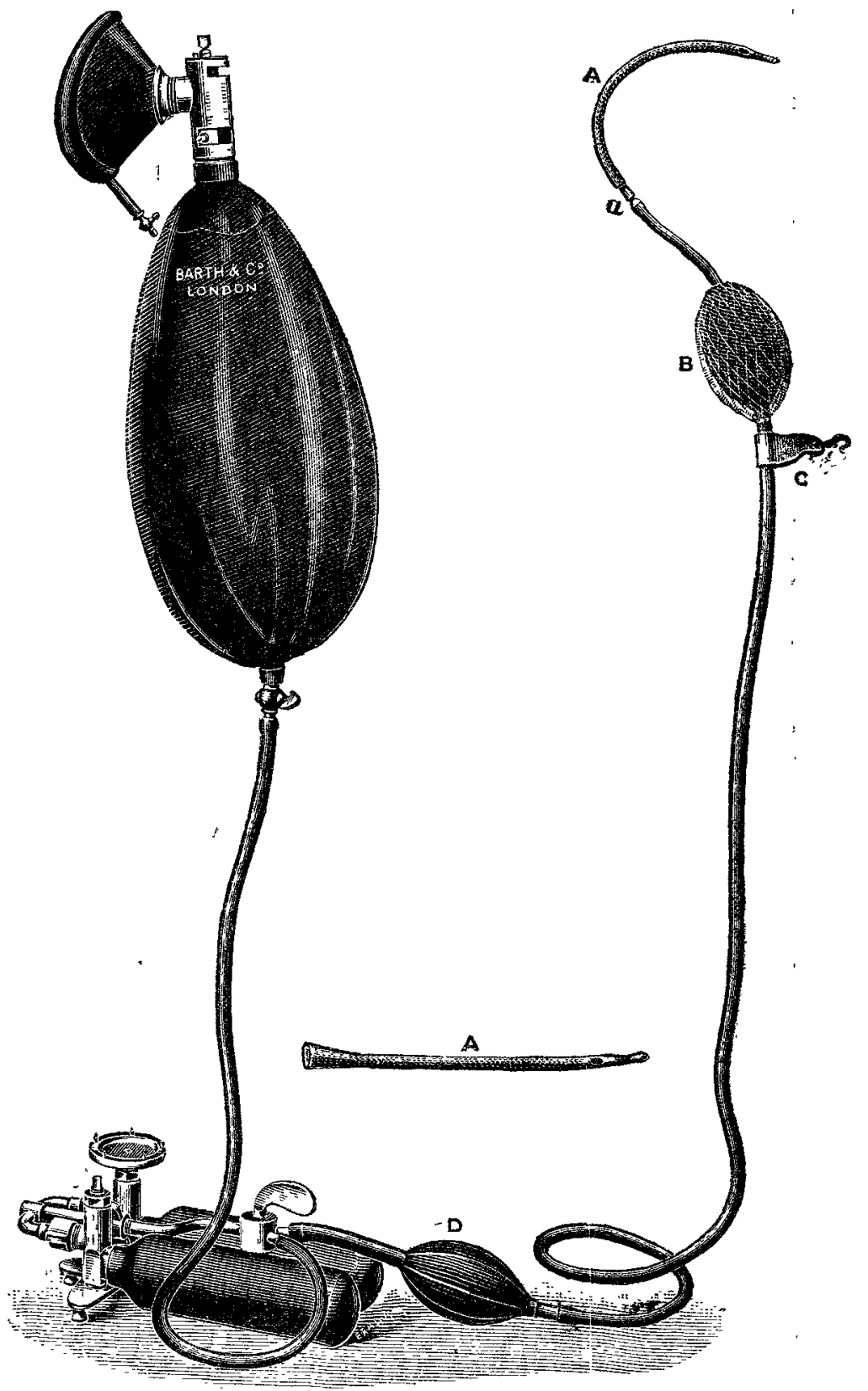

A, Nasal tube ; a, Vulcanite nozzle. B, Netted bag. c, Hook for fixing to head-piece of chair. D, Expansion bag.

number of patients are found to have a deviated nasal septum, an unusually arched palate, causing a corresponding carve of the floor of the inferior meatas, or mach depressed inferior turbinated bones covered with hypertrophied mucosa which would be considerably damaged by the forcible passage beneath them of a rigid instra. ment. Next, a No. 7 (English) soft rubber male catheter was tried. This answers admirably, except that it takes longer to pass and is liable to be blown out by the pressure of gas supplied through it combined with the patient's expiratory efforts, and also on account of its flexibility it is more difficult to keep out of the operator's way without kinking. Lastly, a soft gum elastic silk tube was employed. This tube is equal in diameter to a No.? catheter; it is six inches in length and its distal end is made like an $\grave{a}$ boule male catheter. This is solid up 
to the orifice, which is situated half an inch from the point, the proximal end being expanded to receive the conical attachment of tubing, in connexion with the portable steel oplinders in which the gas is usually stored. Two of these cylinders are connected up in the usual manner and fitted with a stopcock which has been made to my design by Messrs. Barth and Co. It is a tabe of inlet to a stopcock chamber which is screwed into the cylinder connexion and lies in the space between the cylinders so as to be out of the way. This chamber is fitted with a two-way stopcock, the tap of which is an elongated broad arm, so that it can be easily turned by the foot. From the chamber lead two tubes of exit. The tap is so arranged that when it is turned on to either of the two exit tubes the arm lies over that tube through which the gas will flow when liberated from the cylinders by means of the ordinary foot-key. The whole gas supply can thus be entirely controlled by the administrator's foot. The exit tubes, like the other parts of the stopcock, are made of brass, are placed at an angle, and are an inch long, with bulbous ends so that rubber tabing can be easily slipped over them. To one is attached a Dr. Hewitt's gas inhaling apparatus ; to the other the connexions of the nasal tube, which consist of the following:-A small stout rubber "expansion" bag, intended to regulate the usually irregular flow of gas from the cylinders. This is fixed by one end to a stopcock exit, the other extremity being connected by tubing to a thinner and large rubber bag covered with netting, which is continued as a small tube bearing a conical vulcanite nozzle, fitting into the funnel-shaped extremity of the nasal tube proper, $A$. This second bag is fixed by a hook to the head-piece of the dental chair and by noticing its degree of expansion the anæsthetist is enabled to tell whether his patient is getting a sufficient supply of gas to maintain anæsthesia.

The administration is conducted in the usual way until the patient has lost conciousness ; then, taking the precaution that the ordinary gas bag is full, the stopcock having been turned on to it, and choosing the end of an inspiration, the face-piece is removed, the nasal tube is rapidly passed (this can be done during a single expiration), the face-piece is reapplied, and the stopcock is turned, so that the gas now only flows through the nasal tabe; at this stage the inhalation is continued by both nasal tube and facepiece up to full anæsthesia; the face-piece is now finally removed, the operation is begun and narcosis is maintained by the nasal tube alone. To prevent the return of consciousness the "netted bag," B, must be kept fully distended, the gas being supplied at considerable pressure. In a typical case the patient is but slightly cyanosed and there is little or no jactitation (as he inhales sufficient air through the mouth and the free nostril), but the conjunctival reflex is absent. Should, however, he be of the type which requires but little gas, or if for any reason the mouth be considerably obstructed either by sponges or by the operator's hand, the nasal septum being at the same time markedly deviated towards the free nostril, the intake of air in proportion to the intake of gas is so lessened that deep cyanosis, jactitation, and even opisthotonos are produced. If, on the other hand, more gas is necessary to maintain anæsthesia the free nostril can be closed by the anæsthetist's finger or even the mouth can be partially obstructed by inserting a sponge. The extremity of the nasal tube is made to impinge on the posterior pharyngeal wall in order that the flow of gas may be directed by means of the orifice in its under aspect immediately over the npper opening of the larynx, therefore great care must be taken not to permit a very free supply of gas from the cylinder, as by so doing an over-dose would easily be administered.

With this apparatus I have succeeded in keeping patients fally anæsthetised for operations lasting over four minutes and have only then discontinued the administration because the operation has by that time been completed, and not because the anæsthesia could not be further maintained by this method. The tube has been employed in over 100 cases, in 2 of which the operation of tapping and draining the antrum of Highmore was performed and in 1 immediate toreion was exerted upon a lateral incisor tooth. But in a series of 30 consecutive cases of tooth extraction amongst patients of both sexes of which I have made notes the average period of anæsthesia was roughly 1 minute 50 seconds. These cases were chosen as suitable ones for the employment of the tube on account of the necessary extractions being very numerous or appearing to be of unusual difficulty and in only 1 case had the operation to be curtailed ; in this case the hæmorrbage from the gums was so profuse that on this account, after 12 extractions, the operation had to be stopped as no sponges were at hand. The anæsthesia in this case lasted $2 \frac{1}{2}$ minutes. The tube is easily kept ont of the operator's way by being slipped over and behind the patient's ear. There is no fear of conveying sepsis, for the tabe can be sterilised with the greatest ease and in hospital practice $I$ am in the habit of employing two, which are used alternately, so that one can be soaking in antiseptic solution while the other is in actual use. The nostril on the same side as that on which the anæsthetist stands is the more convenient for the passage of the tube, but as the nasal septum is not infrequently deviated to this side one is compelled occasionally to pass the tube along the opposite nostril. The only absolute contraindications to its use are marked hypertrophy of the nasal mucosa or adenoid growths in the naso-pharynz, in either of which cases troublesome bæmorrhage would result from injury to these tissues. Great care must be exercised in passing the tabe so that it can be felt to impinge on the posterior pharyngeal wall, as it is easy to pass it too far and so to inflate the csophagus and set up swallowing movements and vomiting. Even where due cantion is practised vomiting seems to be less uncommon than in ordinary nitrous oxide anesthesia and for this reason patients should be recommended to abstain from food for two or three hours before the administration. If this precaution be taken and one is careful also that the patient swallows no blood, unpleasant after effects will be very rarely met with.

In conclusion I claim for this apparatus that it will render the employment of ether unnecessary in dental surgery; that owing to its small bulk and great portability it is more convenient and economical as regards the quantity of nitrous oxide used than any other apparatus employed with the same object; and, finally, that in skilled hands it is free from the risk of damage to the nose, the naso-pharynx, or the mouth and is without danger to the patient.

Welbeck-street, $\mathbf{W}$.

\section{A CASE OF OVARIOTOMY IN WHICH A PRIMARY OVARIAN AND SIX OMENTAL DERMOID CYSTS WERE REMOVED.}

BY J. LACY FIRTH, M.S. LoND., F.R.C.S. EiNG., ASSISTANT SURGHON TO THE BRISTOL GENERAL HOSPITAL.

A WOMAN, aged thirty-eight years, was admitted under my care at the Bristol General Hospital on Sept. 18th, 1897, complaining of abdominal pain and swelling. She had been married fifteen years, but had had no children and no miscarriages. Menstruation had been regular with one exception throughout her married life. The exception was that she missed three periods a year after marriage. She had at that time a three months' illness, which she called "inflammation of the bowels." The pain then was chiefly in the right. iliac fossa. A month before admission the patient had been suddenly seized with abdominal pain when walking in the street. It was in the hypogastric and left iliac regions chiefly. With the pain came abdominal swelling. The swelling had steadily increased since. Vomiting had been frequent and she had lost flesh and strength rapidly. Careful inquiry elicited that from time to time during some months before the onset of ber present illness she had suspected that the lower part of the abdomen was enlarging. She had had diarrhœea also, though not severely, for three weeks. On admission the patient was sallow and greyish and she looked anxious. The temperature was $100^{\circ} \mathrm{F}$. and the pulse was 95. The abdomen was symmetrically distended in the lower half from the symphysis to a level of 2 in. above the umbilicus. The distended region was moderately tense, very tender, especially in the left iliac region, dull on percussion, and yielded a slightly marked thrill when tapped. There was a corona of resonance around it in the flanks and epigastrium. It was central. A softish mass, slightly moveable upwards and downwards, was felt lying across its upper and front part. It was thought to be an adherent coil of intestine (probably it was the thickened omentum containing secondary dermoids). 